\section{How to keep secrets}

The United States should be more flexible about the flow of militarily sensitive technology.

THE Reagan Administration is making a muddle of its revision of the Export Administration Act, the measure that will regulate the export of technology with military implications. Long before the original version was due to expire last September (it has been extended), the administration was openly complaining about the rules it had inherited. It is now more than two years since Admiral Bobby Inman, then still with the Pentagon, startled academics with the statement that the flow of militarily important information from the United States to the Soviet Union constituted a haemorrhage and that if universities did not volunteer a mechanism for abating the flow, they would find one thrust upon them. That is what is now happening, to judge from the threat by several research universities that they will accept no more research contracts from the Pentagon if foolish restrictions on publication are enforced (see opposite). Most people's instinctive reaction will be to blame the Pentagon for its failure to understand the character of academic science. Blame attaches, but the issues are too complicated for the blame to be unalloyed.

The need for legislation of some kind is regrettable but not disputed, except by the Soviet Union. National defence has become so bound up with technology that all governments seek to keep potentially valuable secrets to themselves. The Soviet Union has the simplest and most effective arrangement there could be. Military research and development is kept strictly separate from civil research and development, with the consequence that the technical community is split into two and that the pace of civil development is slower than it would otherwise be. Such a rigid division between military and civil work would be intolerable in most Western countries for two reasons: the rigidity of the Soviet system is an offence against people's liberty, but the restraint of civil development is both unnecessary and intolerable. So much is widely understood. It is less widely appreciated that shading of the separation between military and civil research and development can be purchased only at a price - leakage of information and even products.

\section{Tension}

This principle is implicit in the arrangements that have grown up in recent decades in the West for regulating the flow of technology to the East. There is a NATO-based organization called COCOM that maintains a list of products in which trade shall not be free. Governments which honour the embargo need domestic legislation allowing them to determine how their own companies should conduct their export businesses, which is partly what the Export Administration Act is for. What the US Congress needs to appreciate is that the system for operating the strategic embargo has never worked smoothly, and never will. In the strictly commercial field, where what matters is the export of products, there are several sources of tension between the United States and its partners. First, perceptions differ on the urgency of the strictly military threat. Second, there is a continuing dispute on the degree to which strategic embargoes should be devised for economic rather than military reasons. Third, many companies and governments in Western Europe regard Eastern Europe and the Soviet Union as the principal markets for technologically advanced products which are accessible to them. Finally, there are suspicions that the strategic embargo can be used by the United States as a means of putting other Western companies and governments at a disadvantage, especially in the sale of goods made in Western Europe under licence from the United States.

Congress has entered into the revision of the act with the gusto expected in an election year. The result is that the Senate and the House of Representatives have emerged with bills so laden with contradictory amendments that it is hard to see how they can be reconciled. On some issues, the administration has been helpful, and on the side of the angels. Now, for example, the suspension of all trade with the United States will not be the automatic penalty for a Western European government judged (in Washington) to have administered the strategic embargo loosely. But in a year when there is some electoral benefit to be won by those who let their constituents know clearly where they stand in relation to countries overseas, the temptation to burden the bill with toughtalking amendments has been irresistible. Both the administration and Congress must, however, share responsibility for the most obvious weakness of what they are planning, their failure openly to recognize that in the West, no strategic embargo can aim at complete prohibition. The best that can be done is to keep the flow of goods and information at such a level that the natural pace of development in the West will always outdistance the advantages gained from leakiness.

\section{Computers}

How is such a principle to be applied to information as well as to the export of goods and services? Hitherto, the COCOM mechanism has at least been a forum in which contentious issues can be resolved between the United States and its partners in the enterprise. What has worried Western Europe in the past few years has been the tendency in the United States to a rigid interpretation of technological advantage. Computer equipment naturally features on the embargo list for example, and there would undoubtedly be great strategic significance in, say, the export of machines for making microprocessors, but in this respect the interests of the military and commercial secrecy luckily coincide. On the other hand, there is very little of strategic value to be learned from a few example of hardware put on the markets in the West five or so years ago that cannot just as easily be learned from the open literature. Much the same is true of another fashionable field, the manufacture of novel materials. The fact that, with the passage of time, many innovations in such fields are found to have been used in the manufacture of Soviet equipment is neither here nor there. All that should matter is that the time-lag should be long enough to ensure that techniques in the West have moved on another notch.

This is the point at which the US academic community has something to offer the administration. In the past few months, with the growth in the number of supposedly public conferences which have been restricted to US nationals, it has become plain that too many decisions about the administration of the whole system have been left to officials who are plainly ignorant of the realities of technological innovation, and of the comparative ease with which innovations once launched may be imitated elsewhere. Is it too much to ask, even at this late stage, that the administration should engage the academic community in a serious attempt to define the effectiveness of policies such as those now being followed? Some case histories would help, as would a serious study of the two-way flow of information between the United States and Japan on the development of microelectronic devices. (The officials responsible for excluding non-US nationals from conferences in the United States seem unaware of the numbers of Japanese names with which conference programmes of the IEEE are now littered.) And it should be possible to make some qualitative assessment of the degree to which the inhibition of the free flow of information may damage technological innovation even in the United States.

At some level, however, that is the coinage in which the price of secrecy must be paid. Reports that some research universities in the United States will not accept research contracts if normal publication of results is seriously inhibited are merely a proof of that. For many universities in the United States and their faculties, this is an issue that cannot be fudged. Senator Jesse Helms' amendment to the Export Administration Act is bound, if it stands, to force such a confrontation. But there is no reason to think that the universities in this dilemma are disloyal to the administration, or anxious to see some other power prosper. The essential difficulty is that the definition of what information is sensitive cannot be left by self-respecting academics to nameless officials in some government office. Here again the need is for a forum for framing definitions that command the respect of those affected. 